\title{
OS CONFLITOS DO GERENCIAMENTO DA ÁGUA MINERAL NO BRASIL - ESTUDO DE CASO: ESTADO DO RIO DE JANEIRO
}

\section{THE CONFLICTS OF MINERAL WATER MANAGEMENT IN RIO DE JANEIRO STATE, BRAZIL}

\section{Lucio Carramillo Caetano ${ }^{1}$, Sueli Yoshinaga Pereira ${ }^{2}$, Francisco Dourado ${ }^{3}$}

\author{
${ }^{1}$ Doutor, Instituto de Agronomia da Universidade Federal Rural do Rio de Janeiro - \\ Rio de Janeiro, RJ. E-mail: carramillo@gmail.com \\ ${ }^{2}$ Doutora, Instituto de Geociências da Universidade de Campinas - Campinas, SP. E- \\ mail: sueliyos@ige.unicamp.br \\ ${ }^{3}$ Mestre, em Geociências Departamento de Recursos Minerais DRM - Rio de Janeiro, \\ RJ.E-mail: fdourado@drm.rj.gov.br
}

\begin{abstract}
RESUMO
Atualmente, os conflitos para a inserção da água mineral na gestão dos recursos hídricos decorrem dos diferentes momentos da história da política brasileira. A legislação de água mineral (Código de Águas Minerais de 1945 e Código de Mineração de 1967) originou-se em governos com políticas centralizadoras, enquanto que a legislação de recursos hídricos (Constituição Federal, de 1988 e a Política Nacional de Recursos Hídricos, de 1997) possui um caráter democrático, descentralizador e multiparticipativo. Este estudo baseou-se numa análise geral dos registros históricos da evolução política, fundamentado na Constituição Federal e legislações referentes a recursos hídricos e minerais. Estes conflitos são muito complexos e graves, principalmente causados pelas seguintes razões: 1) a água mineral é considerada um minério e, legalmente, não faz parte do ciclo hidrológico; 2) áreas de exploração mineral e requeridas estão bloqueadas para uso e ocupação, e 3) áreas mineradas cobrem grandes extensões de municípios, restringindo o crescimento de cidades e ocupando áreas de proteção ambiental; 4) a criação de regulamentações técnicas para o atendimento das necessidades da mineração causam conflitos com outras instituições de outros ministérios, estado e municípios, como o Ministério da Saúde, SERLA-RJ e corpo de bombeiros. Este trabalho conclui que há uma necessidade de criação de parcerias interinstitucionais para o gerenciamento da explotação da água mineral, de acordo com as competências específicas. O gerenciamento maior da explotação dos recursos naturais estaria sob a responsabilidade do ministério (Ministério de Minas e Energia).
\end{abstract}

Palavras-Chave - Legislação Mineral. Política Mineral. Legislação de Recursos Hídricos. Água Subterrânea.

ABSTRACT

Nowadays conflicts for the insertion of mineral water in the management of water resource are originated in models formulated at different moments of the Brazilian political history. The mineral 
water legislation (Mineral Water Code, 1945 and Mining Code, 1967) was created into centralized political governments, while the legislation of water resource possesses democratic, decentralized and multi-participative features (Federal Constitution, 1988, and Water Code, 1997). This study comes from an overall analysis of the historical registration of the policy evolution, which was based on the Federal Constitution and the Legislation regarding both mineral and water resources. These conflicts are very complex and fateful, mainly caused by the following reasons: 1) mineral water has been considered an ore, and legally it is not regarded as part of the water cycle; 2) mining areas and area with titles requested for mining have been blocked for land use, and 3) mining areas cover large extensions of the municipalities, constraining cities growth and occupying environmental protecting areas; 4) the creation of supplementary technical rules to attend present needs has caused conflicts with other ministry, state and municipality institutions, as Health Ministry, SERLA-RJ and fire department. This paper concludes that there is a need for inter institutional partnerships to manage the mineral water exploitation, according to their specific competences. The general management of the natural resources exploitation will be under the responsible Ministry (Energy and Mining Ministry).

Key words: Mineral Law. Mineral Policy. Water Resources Management. Groundwater.

\section{INTRODUÇÃO}

As mudanças de políticas geralmente se adéquam aos momentos históricos que a sociedade e o país passam. A Política Nacional de Recursos Hídricos, preconizada pela Lei 9.433/1997 (BRASIL, 1997), definiu a gestão integrada de recursos hídricos, bem como a gestão participativa, que tem vertente democrática e descentralizadora.

No caso da gestão das águas subterrâneas, no entanto, a implantação de políticas ainda é incipiente e atualmente existem muitos problemas a serem resolvidos. Em nível federal, nos últimos anos, foram discutidos na Câmara Técnica de Águas Subterrâneas no Conselho Nacional de Recursos Hídricos, os conflitos existentes entre a água mineral e água subterrânea. De acordo com a Política Nacional de Recursos Hídricos, a Lei 9.433/1997 (BRASIL, 1997), a água subterrânea, apesar de possuir um valor econômico, é de domínio público e de gerenciamento dos estados. A água mineral, também uma água subterrânea, no entanto, é considerada minério, pelo Código de Minas, Decreto $n^{\circ}$ 24.642/1934 (BRASIL, 1934), e pelo Código das Águas Minerais, Decreto-lei $\mathrm{n}^{\circ}$ 7.841/1945 (BRASIL, 1945), possui valor de mercado, e é gerenciada pela administração federal, o Departamento Nacional de Produção Mineral (DNPM) do Ministério de Minas e Energia.

Estas diferentes abordagens e políticas para águas de mesma origem apresentam conflitos de gestão territorial pública (municipal, estadual e federal) e interinstitucional.

Ainda, a visão compartimentada de um recurso que faz parte do ciclo hidrológico, provoca conflitos e problemas que agora estão se tornando visíveis e de difíceis soluções, uma vez que envolvem muitos interesses tanto dos usuários (empresários e consumidores), como de tomadores de decisão.

O Código de Mineração, Decreto-Lei 227/1967 (BRASIL, 1967), em geral, apresenta problemas de conflitos, principalmente na questão de requisição de áreas (poligonais) reservadas exclusivamente para a exploração do minério. Isso significa que grandes áreas são requeridas, e muitas vezes conflitam com os planos diretores municipais e áreas de mananciais de recursos hídricos.

Este trabalho visou, por isso, apresentar um cenário, ainda que incompleto, face à complexidade do assunto dos principais problemas que estão ocorrendo na implantação e organização de processos de gerenciamento dos recursos hídricos, ênfase nos subterrâneos, no gerenciamento da água mineral. 


\section{MATERIAL E MÉTODOS}

A metodologia utilizada foi baseada na pesquisa documental: 1) das informações do Departamento Nacional de Produção Mineral (DNPM), de seu cadastro das áreas requeridas tanto para a fase de pesquisa mineral como já em atividades de lavra, para água mineral e outros minérios no estado do Rio de Janeiro; 2) de legislações e normas/portarias/resoluções/instruções federais, estaduais e municipais referentes à água mineral; 3) dos documentos requeridos para a implantação de uma indústria de água mineral, em nível federal, estadual e municipal, e 4) na busca da função de diversas instituições (de diferentes áreas) e sua participação na gestão da água mineral.

A análise consistiu em determinar, na leitura dos documentos, os principais conflitos existentes em relação às funções de diferentes instituições e poderes que se sobrepõem.

$\mathrm{Na}$ espacialização das informações, as poligonais das áreas requeridas para fase de pesquisa e concessão de lavra foram então cruzadas com os contornos municipais e Unidades de Conservação (de uso direto e de uso indireto), por meio de um Sistema de Informação Geográfica (SIG).

As fontes de informação que compuseram as cartas geradas foram: (a) Instituto Brasileiro de Geografia e Estatística, IBGE (2012) - base da malha dos municípios; (b) Instituto Estadual do Ambiente, INEA-RJ (2011) ï Unidades de Conservação, e (c) DNPM (2012) ï as poligonais das áreas com direitos minerários.

Uma extensa pesquisa sobre as legislações/ decretos-lei e normas/ portarias/ resoluções/ instruções federais e estaduais referentes à água mineral foi realizada no intuito de entender todos os processos, e poderes setoriais, e conflitos apresentados neste trabalho (a nível federal estadual e municipal). Assim, leis, decretos-lei, resoluções e portarias, relativas à água mineral foram analisadas, compreendendo desde a constituição brasileira a portaria estadual, abrangendo governo federal e ministérios/ instituições, e governo estadual com suas secretarias e instituições. A busca destas referências legais foi feita em endereços eletrônicos e nas instituições envolvidas; o critério principal da análise foi a procura pelas mesmas competências em diferentes setores e instituições. A Tabela 1 apresenta as documentações legais analisadas e utilizadas no presente trabalho.

Tabela 1 - Documentações legais (Constituição, Leis, Decretos-lei, Resoluções, Portarias) federais e estaduais utilizadas.

\begin{tabular}{|c|c|}
\hline \multicolumn{2}{|c|}{ Documentação legal analisadas e referenciadas } \\
\hline Federal & 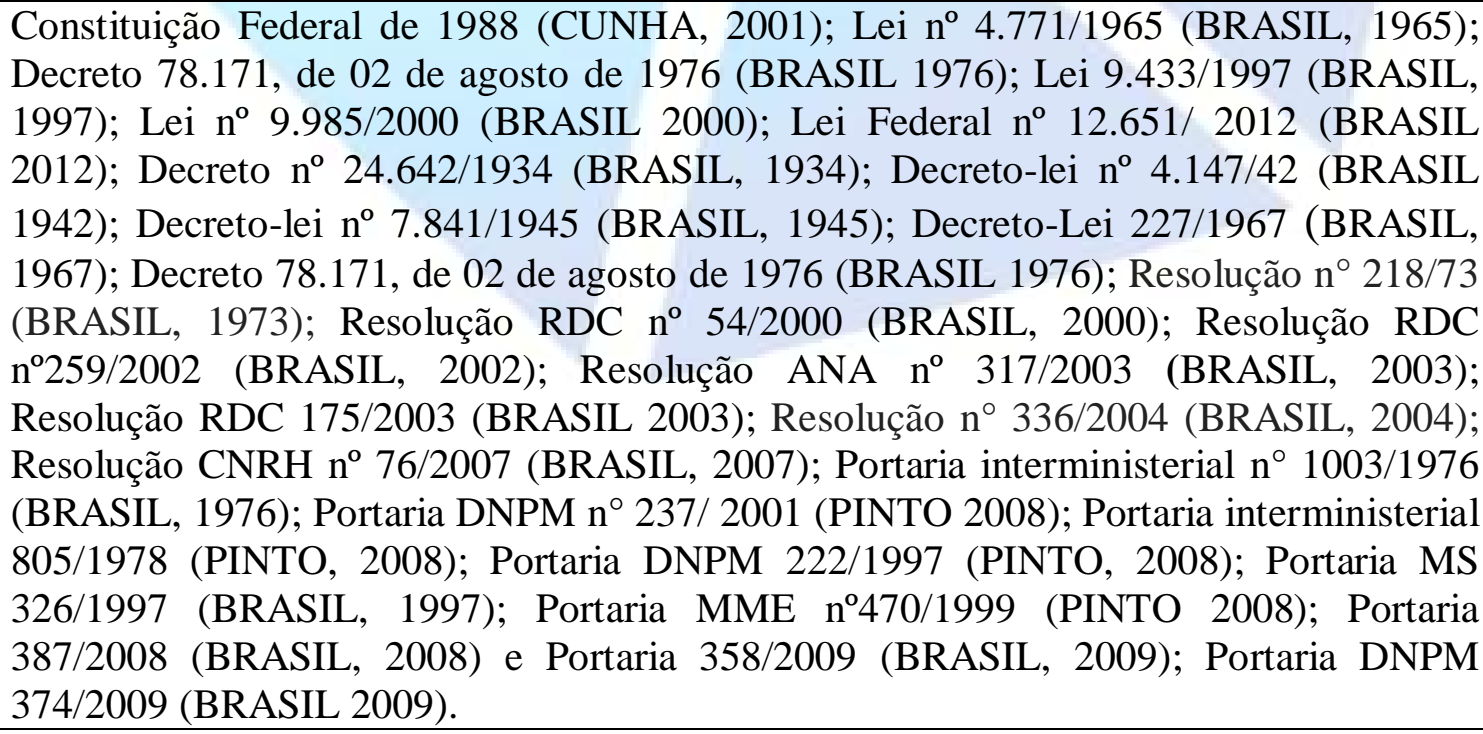 \\
\hline Estadual & Lei Estadual no 3.239/1999 (RIO DE JANEIRO, 1999) \\
\hline
\end{tabular}




\section{RESULTADOS E DISCUSSÃO}

Os problemas e conflitos aqui mapeados são complexos e diversos, uma vez que a água mineral, por um dispositivo legal criado em 1945 é um minério, pelo Decreto-lei $n^{\circ} 7.841 / 1945$ (BRASIL, 1945). A água mineral, no entanto, pode ser tratada também como alimento (pois há consumo humano envolvido, no caso da água mineral envasada e para ingestão na fonte), e por ser consumida, também deve ser fiscalizada por órgãos da saúde.

Por ser um recurso hídrico, apresenta conflitos com a Política de Recursos Hídricos, pois ela não legisla sobre a água mineral, pois de acordo com legisladores, essa água é desvinculada da água subterrânea, pois não é considerado recurso hídrico. Estes conflitos e assertivas legais são bem discutidos por Caetano (2005) e Serra (2008).

Desde a promulgação da Constituição Federal de 1988 (CUNHA, 2001), que incluiu as águas subterrâneas entre os bens dos Estados, e da Lei 9.433/1997 (BRASIL, 1997), que Institui a Política Nacional de Recursos Hídricos, inicia-se um processo de discussão a respeito da gestão integrada da água. Este assunto foi polemizado e como resultado de várias reuniões e discussões na Câmara Técnica de Água Subterrânea, foi elaborada a Resolução nº 76/2007 do Conselho Nacional de Recursos Hídricos (BRASIL, 2007) que propõe a integração da gestão de recursos hídricos e das águas minerais.

Este assunto polêmico é analisado por Hager e D’Almeida (2008), que discutiram a questão das águas subterrâneas e a água mineral no contexto da Constituição, e consideram que há uma interpretação não válida sobre a questão de dominialidade. A água mineral é recurso hídrico e recurso mineral, e assim consideraram que a Política Nacional de Recursos Hídricos (BRASIL, 1997) poderia integrar procedimentos sem mudança de competência ou enfraquecimento de um ou outro setor. Ainda consideram que o termo mineral é qualificador de uso, pois se pode utilizar a mesma água para lavagem ou abastecimento. Affonso e Monsores (2004) consideraram que não existem conflitos entre normas de estados e união, pois as águas subterrâneas seriam classificadas como mineral quando atendem aos requisitos legais dispostos no Código das Águas Minerais, que garante a legitimidade para outorga de direito de usos à União. Quando contaminada, por exemplo, a característica mineral se perde e assim deve ser considerada como recurso hídrico e sua dominialidade passa aos Estados-membros.

Scalon (2011) fez uma análise sobre a questão das águas minerais e recursos hídricos, de seus instrumentos de fiscalização e controle, e que o ordenamento jurídico brasileiro conferiu às águas minerais um abrigo singular devido as suas especificidades. Por isso considera-se que não é necessária então a outorga de direito de uso de recursos hídricos; aprovando a Resolução n 76/1997 do Conselho Nacional de Recursos Hídricos (BRASIL, 1997) que prevê a gestão integrada de recursos hídricos e águas minerais, e recomenda que a colaboração mútua e articulada entre o DNPM e os órgãos gestores estaduais deve ser estimulada.

Assim, os seguintes conflitos são discutidos neste trabalho:

- Territorial ï os conflitos entre as áreas requeridas para mineração da água mineral e o território (municípios e mananciais);

- Institucional federal ï (a) órgãos de gestão mineral (DNPM); (b) órgãos de saúde (Agencia Nacional de Vigilância Sanitária - ANVISA); (c) órgãos de meio ambiente (Instituto Brasileiro do Meio Ambiente e dos Recursos Naturais Renováveis - IBAMA e Instituto Chico Mendes); (d) órgãos de recursos hídricos (Agência Nacional de Águas ANA);

- Institucional estadual ï (a) órgãos da saúde (Vigilância Sanitária - VISA); (b) órgãos estaduais de meio ambiente; (c) os órgãos estaduais de recursos hídricos; d) corpo de bombeiros do estado.

- Institucional municipal ï prefeituras e secretarias municipais. 
- Conselhos Profissionais ï Conselho Regional de Engenharia e Agronomia (CREA) e Conselho Regional de Química (CRQ).

O Estado do Rio de Janeiro tem grande parte do seu território bloqueado por direitos minerários (Figura 1). Do seu total territorial de 43.793,56 Km², 22,05\% $\left(9.658,61 \mathrm{Km}^{2}\right.$ ) apresentase requerida ou titulada para minérios. A maior incidência de títulos minerários situa-se na porção norte do Rio de Janeiro, próximo da fronteira com o estado de Espírito Santo, e na região da Região Metropolitana do Rio de Janeiro.

A água subterrânea é um recurso hídrico de domínio estadual e por isso necessita de outorga, no caso, do Instituto Estadual do Ambiente (INEA-RJ), por meio da Lei Estadual $\mathrm{n}^{\circ}$ 3.239/1999 (RIO DE JANEIRO, 1999). No entanto a água mineral não necessita de outorga, uma vez que é considerada minério e está subordinada ao DNPM, pelo Código das Águas Minerais (BRASIL, 1945). No caso, apenas há necessidade de se fazer o cadastro da captação (Cadastro Nacional de Usuários de Recursos Hídricos - CNARH), junto à ANA, pela Resolução ANA no 317/ 2003, (BRASIL, 2003).

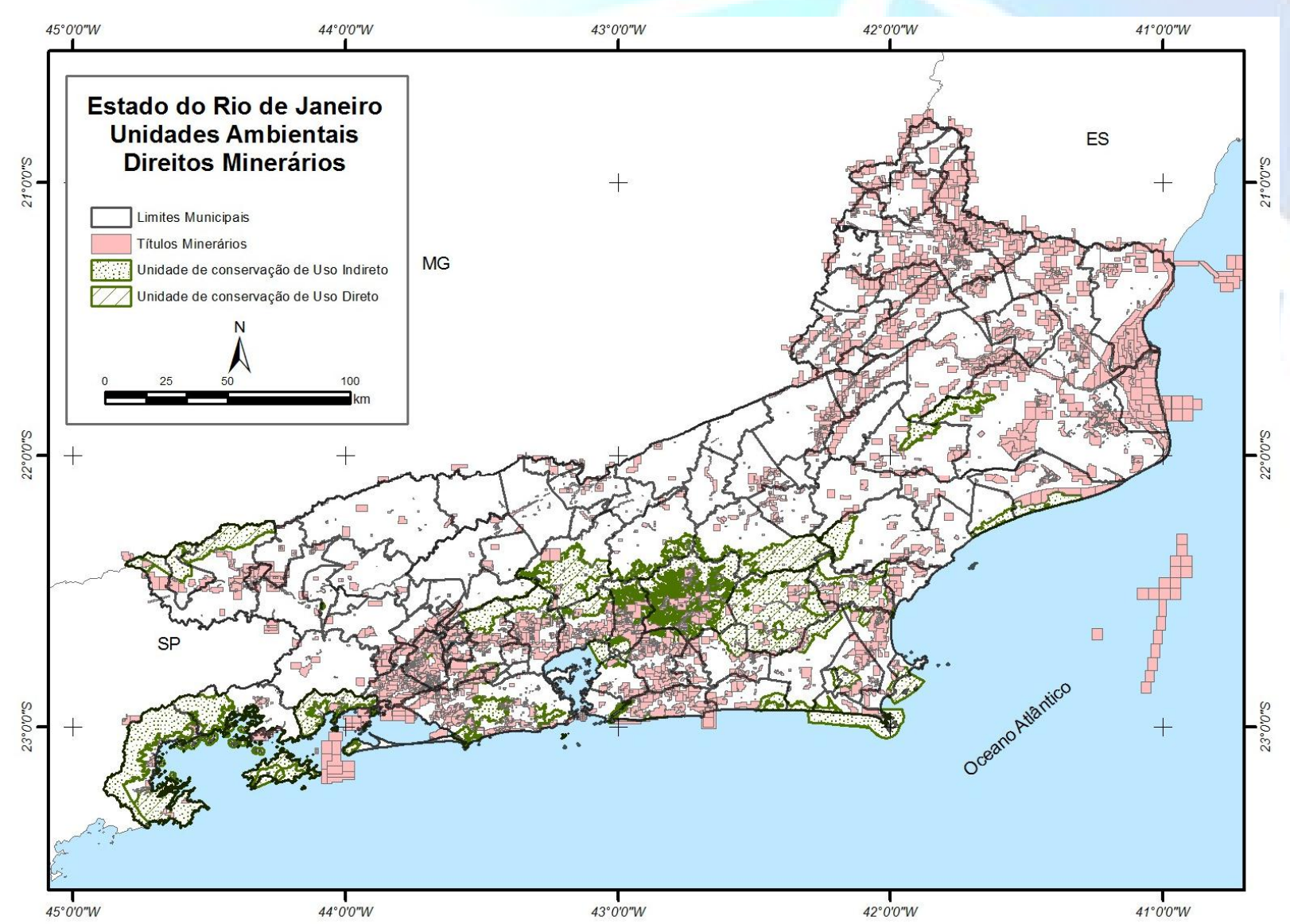

Figura 1. Áreas do território do estado do Rio de Janeiro bloqueadas por direitos minerários (atualizado até 2011).

Fonte: SIGMINE (http://sigmine.dnpm.gov.br/sirgas2000/RJ.zip, acesso: 15/05/2012); IBGE (2007) e INEA-RJ (http://www.inea.rj.gov.br/unidades/conteudo.asp, acesso em 19/10/2012). 


\subsection{Setor Mineral e Saúde}

Os conflitos entre o DNPM e as Secretarias de Estado de Saúde deram início, a partir da Constituição e da promulgação do Código de Minas de 1934, Decreto no 24.642/1934 (BRASIL, 1934), quando foi passada para competência privativa da União legislar sobre riqueza do subsolo, mineração e água, que até então eram considerados bens dos Estados.

De 1934 até 1976 (42 anos), os poderes das Vigilâncias Sanitárias eram limitados, por força de Decretos-Lei, ainda da época do governo de Getúlio Vargas.

Com a promulgação do Decreto 78.171/1976 (BRASIL 1976), as Secretarias de Estado de Saúde retornam às suas funções de análise e fiscalização das indústrias de água mineral.

Esse Decreto deu início a uma série de legislações, iniciadas por portarias interministeriais dos Ministros de Minas e Energia, e da Saúde, e de diversas portarias e resoluções do Ministério da Saúde. Essas possuíam a finalidade de regulamentar o setor, em relação a padrões de higiene e qualidade da água mineral para consumo humano, bem como delimitar poderes entre as atribuições dos dois Ministérios (Saúde e Minas e Energia).

A partir de 1976, os conflitos entre os dois órgãos (DNPM e Saúde) foram ampliados por legislações aprovadas sobre o mesmo assunto, que determinavam ações fiscalizadoras e de legalização diferenciadas que interfere com a competência da Saúde.

Mesmo com o Decreto-lei ${ }^{\circ} 78.171 / 1976$ (BRASIL, 1976a) e as Portarias interministeriais $\mathrm{n}^{\circ}$ 1003/1976 (BRASIL, 1976b) e 805/1978 (PINTO, 2008) em vigor, o DNPM, baseando-se na competência a ele estabelecida pelo Decreto-Lei $\mathrm{n}^{\circ}$ 7.841/1945 (BRASIL 1945), assume ainda competências que pertencem à Saúde. Dessa forma, alguns conflitos são apresentados abaixo:

- O controle sanitário da qualidade das águas minerais destinada ao consumo humano, bem como a fiscalização sanitária dos locais e equipamentos relacionados com a comercialização do produto são competências do Ministério da Saúde das Secretarias de Saúde dos Estados e Distrito Federal pelo Decreto $\mathrm{n}^{\circ}$ 78.171/1976 (BRASIL, 1976). No entanto existe um procedimento ainda atuante pelos empresários da indústria de água mineral de atendimento ao Decreto-lei $\mathrm{n}^{\circ}$ 4.147/1942 (BRASIL 1942).

- A Portaria 222/1997 do DNPM (PINTO, 2008) apresentou conflito com a Portaria 326/1997 do Ministério da Saúde (BRASIL, 1997), pois ambos estabelecem procedimentos para as condições higiênico-sanitárias e exames ambulatoriais e laboratoriais dos funcionários, sendo que essa última é mais detalhada.

- A Portaria n470/ 99 do Ministério de Minas e Energia (PINTO 2008) e a Resolução RDC n²59/2002 da Agência Nacional de Vigilância Sanitária (BRASIL, 2002) apresentam as características básicas dos rótulos e embalagens de águas minerais e potáveis de mesa, e o regulamento técnico sobre rotulagem. Existem regras estabelecidas pela Saúde que diferem das regras do DNPM/MME, tais como a data de fabricação e validade e a ordem de apresentação da composição química da água;

- O Ministério da Saúde, pela Resolução RDC no 54/2000 (BRASIL, 2000) exige a análise química completa que contemple inúmeros compostos orgânicos, inorgânicos, agrotóxicos, cianotoxinas e desinfetantes e produtos secundários da desinfecção, que não estão contemplados pelas análises, denominados estudos ñin locoò, exigidas pelo DNPM de 3 em 3 anos, pela Portaria no 470/1999 (PINTO 2008);

- O DNPM impõe validade de 3 anos para a embalagem retornável (Portarias 387/2008 e 358/2009, BRASIL 2008 e 2009) enquanto a Saúde apenas indica condições de qualidade para as embalagens sem, no entanto, restringir seu tempo de uso, de acordo com a Resolução RDC 175/2003 (BRASIL, 2003).

Deste modo, é frequente a existência de situações em que o fiscal de um órgão determina uma ação que conflita com a orientação ou exigência do outro órgão. 


\subsection{Setor Mineral e o Meio Ambiente}

A figura 1 demonstra a localização dos títulos minerários de água mineral, que compreende $0,34 \%$ da área do território $\left(147,63 \mathrm{Km}^{2}\right)$. Estes se encontram distribuídos irregularmente no território e se concentram na região leste, sul e oeste do estado. Muito destes requerimentos estão dentro ou nas proximidades das Unidades de Conservação de Uso Sustentável (ou Uso Direto) ou de Proteção Integral (ou Uso Indireto). As unidades de conservação de uso direto, ou de uso sustentável, são definidas como as que permitem a exploração e uso sustentável de parcela de seus recursos naturais desde que compatíveis com a conservação da natureza. Já as de uso indireto, mais restritivas são definidas como unidades de Conservação de Proteção Integral, onde deverá haver a conservação dos atributos naturais, com um mínimo de alterações, de acordo com a Lei ${ }^{\circ}$ 9.985/2000 (BRASIL 2000).

Em geral, pela própria natureza do produto, as águas minerais são geralmente captadas de locais cujo entorno seja protegido ou próximo às áreas de vegetação preservada. Assim, as áreas bloqueadas significam exatamente as nascentes de cursos dốgua que, perante a legislação ambiental vigente, deveriam ter a vegetação protegida num raio de pelo menos 50 metros, de acordo com o Código Florestal de 1965, ainda vigente - Lei no 4.771/1965 (BRASIL 1965). A Lei Federal $\mathrm{n}^{\circ}$ 12.651/2012 (BRASIL 2012), em análise e discussão pelo Congresso e Senado Federal, apresenta várias propostas de mudanças na lei, porém mantém as nascentes como Áreas de Preservação Permanente, com raio mínimo de 50 metros em seu entorno.

Pela legislação mineral, além desses serem os melhores pontos para captação, todas as árvores no entorno devem ser retiradas para que a área de proteção da captação seja calçada ou pavimentada, de acordo com o Decreto-Lei $n^{\circ} 7.841 / 1945$ (PINTO 2008) e Portaria DNPM 374/2009 (BRASIL 2009). Apesar de ser considerada uma indústria ñverdeò onde não há produção de efluentes considerados perigosos e seu entorno deva ser protegido, este procedimento em relação às fontes entra em conflito com as unidades de conservação e o Código Florestal.

Entre os conflitos, há também o que estabelece a ordem de procedimentos, em relação à instalação de uma indústria mineral e as licenças ambientais. Apesar da Constituição Federal de 1988 (CUNHA 2001) estabelecer ao poder público, a exigência de estudo prévio de impacto ambiental para a instalação de obra, ou atividades potencialmente causadoras de significativa degradação do meio ambiente (a mineração e a indústria de água mineral estão nesse caso), um dos documentos exigidos pelo órgão ambiental estadual, para liberação da Licença de Instalação, é um parecer do DNPM, informando que o Plano de Aproveitamento Econômico foi julgado satisfatório. Já para a obtenção da Licença de Operação, o órgão de meio ambiente estadual exige a apresentação da Portaria de Lavra. Com o encaminhamento processual, obedecendo a essa ordem, a mineração torna-se uma atividade mais importante que a proteção ambiental, indo contra o que estabelece o item IV, do parágrafo $1^{\circ}$, do art. 225, da Constituição Federal de 1988 (CUNHA 2001).

A figura 2 apresenta os requerimentos de pesquisa, autorizações de pesquisa e concessões de lavra, nas proximidades ou dentro de Unidades de Conservação, exemplo nas unidades de conservação em Cachoeiras do Macacu, situado na região central do estado do Rio de Janeiro. Esta figura mostra as áreas requeridas para exploração mineral (água mineral) nas nascentes dos corpos de água, e nas áreas de proteção permanente, como de cursos de água. 


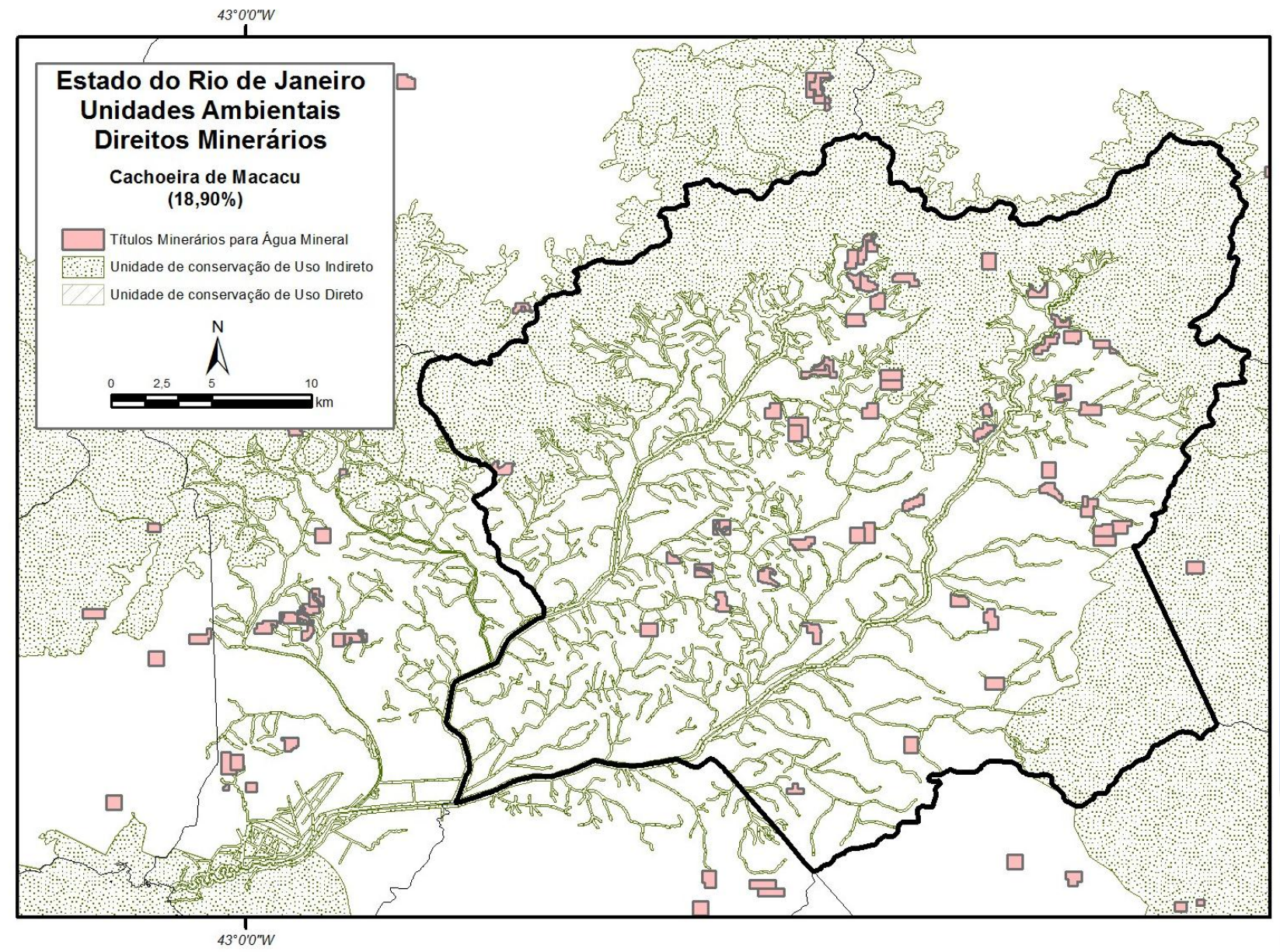

Figura 2. Títulos minerários demonstrando o elevado interesse pela captação de nascentes (surgências) próximas ou dentro das Unidades de Proteção em Cachoeiras de Macacu (RJ)

Fonte: SIGMINE (http://sigmine.dnpm.gov.br/sirgas2000/RJ.zip, acesso: 15/05/2012); IBGE (2007) e INEA-RJ (http://www.inea.rj.gov.br/unidades/conteudo.asp, acesso em 19/10/2012).

\subsection{Setor Mineral e os Órgãos Estaduais de Recursos Hídricos}

Os conflitos entre o setor mineral e órgãos estaduais de Recursos Hídricos iniciaram-se na questão da definição de água mineral e subterrânea. Os órgãos estaduais consideram a água mineral uma água subterrânea, e, portanto um recurso hídrico, que deve ser gerenciado pelos estados. As especificidades da água mineral, no entanto, classificam-na como recurso mineral, e por isso é regida com base nas leis da mineração. Este assunto é bem discutido em Caetano (2005) e Serra (2008).

Ainda, a falta de integração dos dados referentes ao uso da água numa região pode causar problemas como a sobreexplotação, causando prejuízos aos usuários. No estado do Rio de Janeiro, há casos de sobreexplotação provavelmente causados pelo excesso de bombeamento pelo poço de indústria de água mineral durante o período do verão (de maior venda). Apesar da vistoria conjunta do DNPM com o INEA-RJ, não há ainda um acordo de cooperação que evitasse outras situações como essa.

Outro conflito identificado é relativo ao uso da água subterrânea: há empresas que se utilizam de água subterrânea para atividades industriais, e por isso requerem outorga de uso da água nas instituições estaduais (no caso o INEA-RJ). A área da indústria, entretanto, pode ser requerida para aproveitamento de água mineral, ou de qualquer outro mineral, por terceiros, e com autorização de pesquisa homologada, bloquear todo um complexo industrial já montado. Este tipo de conflito já ocorre no estado do Rio de Janeiro e, também, em outros estados, pois gera 
perspectiva de negociação do título minerário, tornando-se esse tipo de situação/conflito rentável ao titular do bem mineral.

\subsection{Setor Mineral e o planejamento territorial em municípios}

Pela Constituição Federal de 1988 (CUNHA, 2001) tornou-se obrigatória, para municípios com mais de 20.000 mil habitantes, a elaboração do plano diretor, que promove o adequado ordenamento territorial e o controle do uso, do parcelamento e da ocupação do solo urbano, que tem por objetivo, ordenar o pleno desenvolvimento das funções sociais da cidade e garantir o bem-estar de seus habitantes.

À medida que os títulos minerários são liberados, sem a anuência do poder público municipal, o plano diretor elaborado pela municipalidade muitas vezes é prejudicado pelas áreas requeridas para a mineração. O título minerário, seja uma autorização de pesquisa, ou uma concessão de lavra, por ser um documento proveniente de instituição federal inibe, por força de lei, a autoridade municipal.

Desta forma, diversos municípios possuem grandes áreas de seu território bloqueadas por títulos minerários. As figuras 3 e 4 mostram como exemplo, o município Bom Jesus de Itabapoana, com $73,26 \%$ de sua área bloqueada por direitos minerários, e Itaocara, com 45,38\% de sua área bloqueada para mineração, seja na fase de requerimento, autorização ou lavra.

Há uma segunda situação em que municípios mais bem estruturados impõem o zoneamento territorial, mesmo quando se tenha um documento proveniente de entidade federal, autorizando uma atividade que interfira com as características do plano diretor municipal e que provavelmente, irá entrar em conflito com o bem-estar social da população.

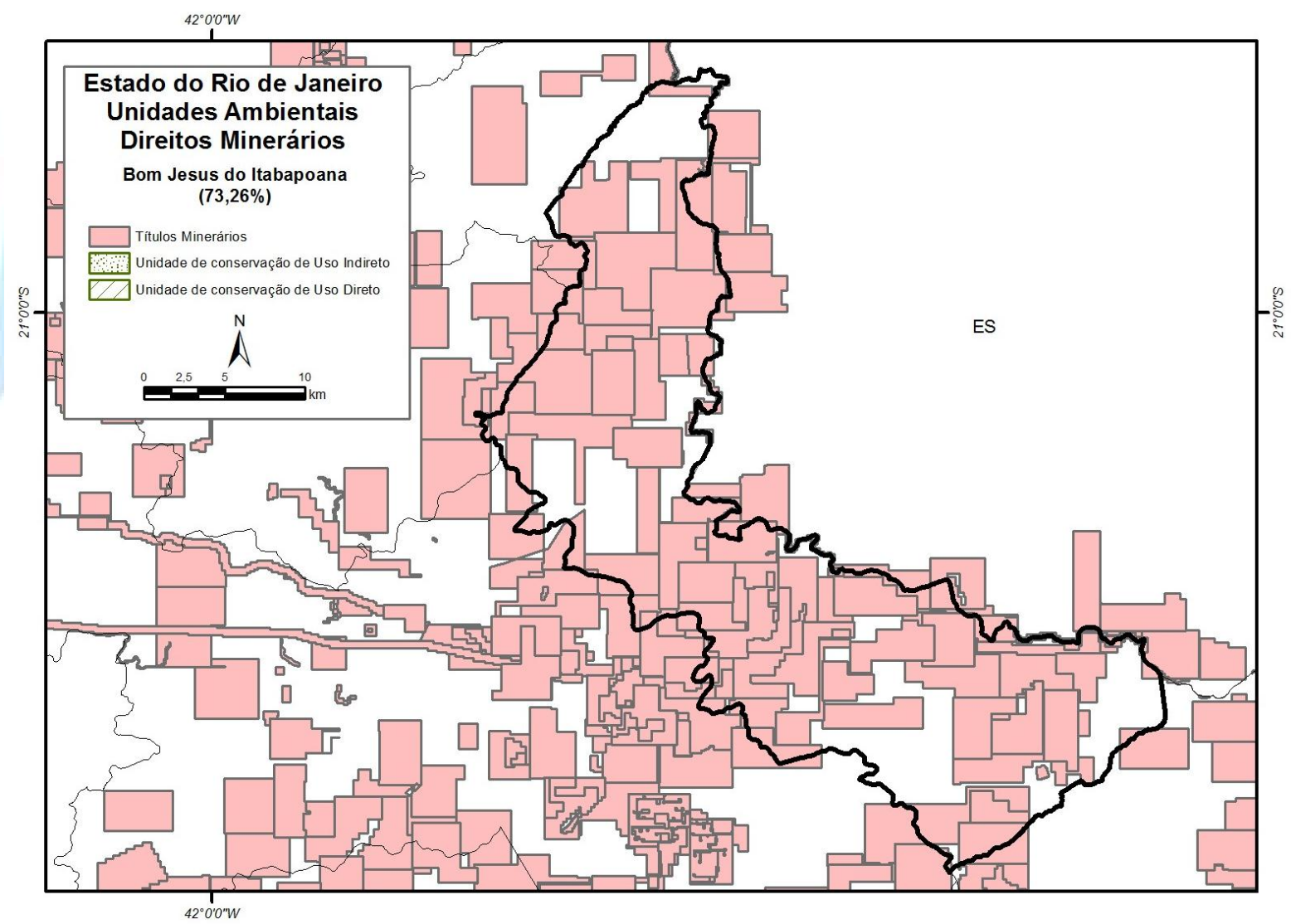

Figura 3. Áreas bloqueadas por direitos minerários no Município de Bom Jesus do Itabapoana (73,26\%) Fonte: SIGMINE (http://sigmine.dnpm.gov.br/sirgas2000/RJ.zip, acesso: 15/05/2012); IBGE (2007) e INEA-RJ (http://www.inea.rj.gov.br/unidades/conteudo.asp, acesso em 19/10/2012). 


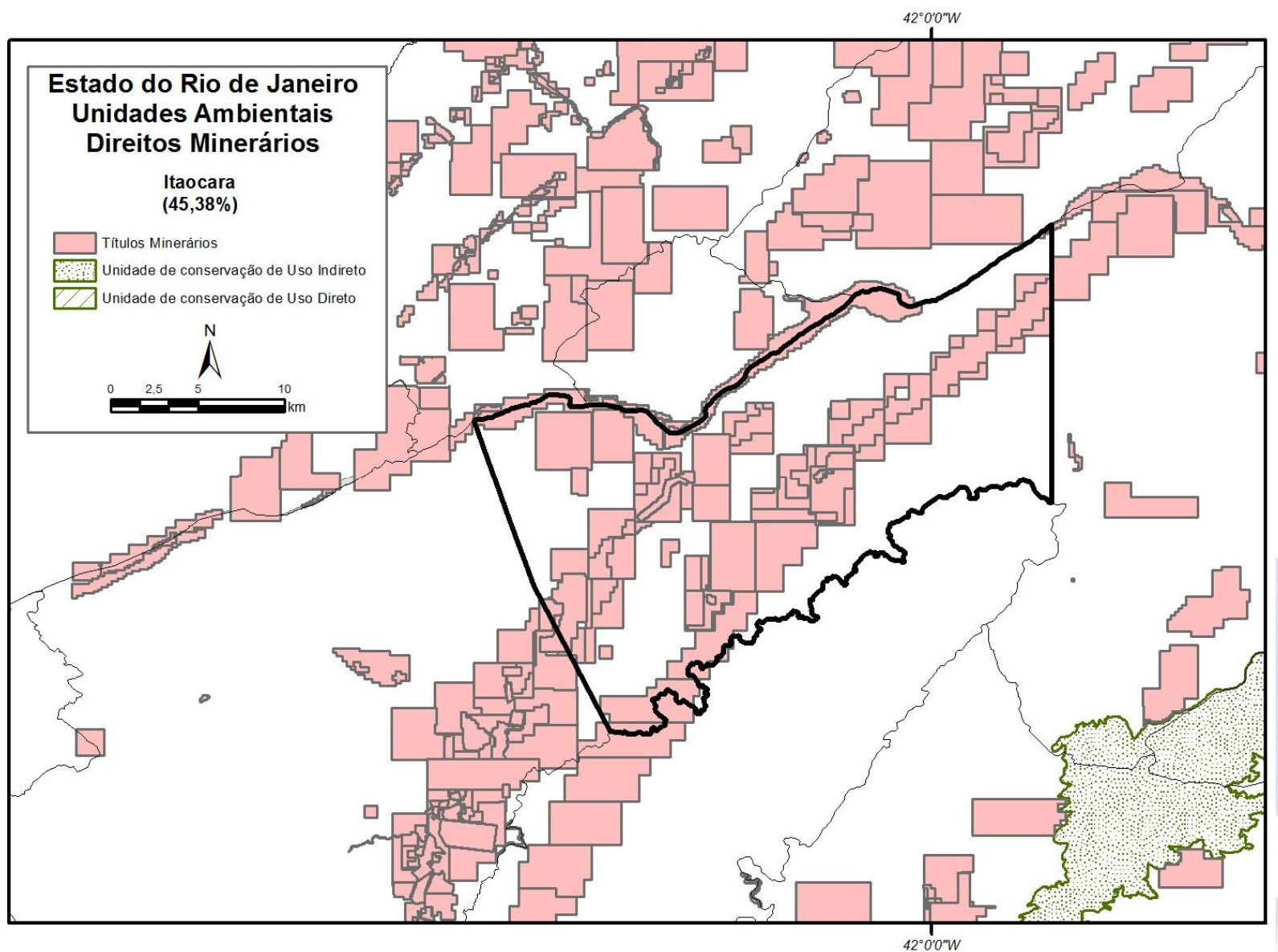

Figura 4. Áreas bloqueadas por direitos minerários no Município de Itaocara $(45,38 \%)$

Fonte: SIGMINE (http://sigmine.dnpm.gov.br/sirgas2000/RJ.zip, acesso: 15/05/2012); IBGE (2007) e INEA-RJ (http://www.inea.rj.gov.br/unidades/conteudo.asp, acesso em 19/10/2012).

\subsection{Setor Mineral e o Corpo de Bombeiros do Estado}

No momento da protocolização do pedido de lavra no DNPM, além do plano de aproveitamento econômico são necessários aqueles para o gerenciamento de riscos, de fechamento de mina e o de resgate e salvamento, de acordo com a Portaria DNPM n ${ }^{\circ}$ 237/ 2001 (PINTO 2008). O Corpo de Bombeiros Militar do Estado do Rio de Janeiro, para fornecer o Alvará de funcionamento, não só exige como verifica o sistema preventivo contra incêndio e pânico.

Assim, também, em relação ao Corpo de Bombeiros, há uma superposição de poderes. Acredita-se que a capacidade técnica do grupamento do Corpo de Bombeiros para analisar esse tipo de projeto, em relação a resgate e salvamento, seja mais adequada e especializada. Dessa forma, entende-se que as Normas Reguladoras da Mineração, Portaria ${ }^{\circ}$ 237/2001 (PINTO 2008), estejam mais diretamente voltadas para processos de mineração típicos e não de uma indústria de água mineral, cujo complexo industrial se estabelece a partir de projetos de envasamento de bebidas. Além disso, é importante ressaltar que órgãos vinculados ao Ministério do Trabalho e Emprego já atuam nessa área, fazendo a fiscalização necessária em relação à obediência das Normas Regulamentadoras de Segurança e Saúde no Trabalho.

O Corpo de Bombeiros e o Ministério do Trabalho e Emprego já exercem atividades de fiscalização no sistema preventivo de combate a incêndio e fuga de qualquer indústria (inclusive a de água mineral). As Normas Regulamentares da Mineração (NRM) do DNPM gera assim um novo conflito a essa atividade, que não possui frente de lavra nem qualquer outra situação típica de mineração. 


\subsection{Setor Mineral e conselhos profissionais}

Já em relação à responsabilidade técnica é importante lembrar que até 1934 o aproveitamento da água mineral não era considerado uma atividade de mineração. Só a partir da promulgação do Código de Minas em 1934, Decreto no 24.642/1934 (BRASIL, 1934), um ano após a regulamentação da profissão de engenheiro de minas, é que a substância água mineral foi enquadrada como uma das jazidas no Código de Minas. Assim, desde 1934, a atividade de pesquisa e extração de água mineral, bem como para as demais substâncias minerais deve ser executada por um engenheiro de minas.

Em relação ao engenheiro de minas, a competência do profissional é atribuída pelo Código de Mineração, Decreto-Lei 227/1967 (BRASIL, 1967), que determina que seja um engenheiro o responsável pela lavra, pelo Código de Águas Minerais, Decreto-lei $\mathrm{n}^{\circ}$ 7.841/1945 (BRASIL, 1945), que considera que a explotação da água mineral é uma mineração, e pelas resoluções do Conselho Federal de Engenharia, Arquitetura e Agronomia (CONFEA): Resolução n 218/1973 e Resolução n 336/2004 (BRASIL, 1973 e 2004).

Com a introdução e a regulamentação da profissão de geólogo em 1966 e a promulgação do Código de Mineração de 1967 (BRASIL, 1967) as atividades de pesquisa podem ser executadas por um desses dois profissionais. Mantém-se, no entanto, a responsabilidade pela extração de água mineral sob a responsabilidade exclusiva do engenheiro de minas, mesmo sabendo-se que a lavra de água mineral não passa de um surgimento natural de água (surgência) ou de um bombeamento de água de um poço. Partindo-se do princípio que ambos, geólogos e engenheiros de minas, estão aptos a se responsabilizar pela captação da água subterrânea (água mineral) com projetos construtivos de poços e testes de vazão (bombeamento), nada os impede de exercerem a responsabilidade técnica desse serviço e registrá-lo no Conselho Regional de Engenharia e Agronomia (CREA). Porém, a atividade de aproveitamento do ñminérioò água passa por diversos processos típicos das atribuições dos engenheiros civis e arquitetos.

Dessa forma o CREA não reconhece aos geólogos e engenheiros de minas as atribuições para projetar, construir galpões de indústria de alimentos (envasamento de água mineral), onde farão parte do projeto salas de envase, antecâmaras assépticas, equipamentos de lavagem de garrafas a quente usando soda cáustica, salas de estoque de produtos químicos (limpeza e desinfecção), laboratório de química e físico-química, laboratório de microbiologia, refeitórios, ambulatório e salas de repouso (tipo enfermaria), entre outras. Tanto a Vigilância Sanitária Estadual, quanto o Conselho Regional de Química (CRQ) e o CREA, admitem que o profissional mais capacitado para esse serviço pertence à área de química ou alimentos. No caso específico da Vigilância Sanitária, é possível que o responsável técnico de uma indústria de água mineral seja um profissional que possua cursos de especialização em indústria de alimentos.

O próprio DNPM utiliza profissionais, com formação acadêmica em química e de nível médio (técnico em mineração), para análise de algumas etapas dos processos e para fiscalização das indústrias de água mineral em todo o Brasil (CAETANO 2005). Dessa forma, acredita-se que a obrigatoriedade do engenheiro de minas como responsável por essa indústria, esteja vinculada apenas à permanência da água mineral no texto do Código de Mineração, não tendo qualquer motivação de capacitação técnica. O DNPM realiza vistorias nas indústrias de água mineral com profissionais de nível médio (técnico em mineração), das áreas de química e geologia, e exige das empresas de água mineral, a apresentação de contrato com engenheiro de minas (CAETANO 2005). Caso as empresas não estejam de posse do contrato no momento da vistoria, considera-se que a lavra não está sendo conduzida por profissional legalmente habilitado e, por esse motivo, é fornecido um prazo para a apresentação do contrato à Superintendência do DNPM ou mesmo lavrado um auto de infração.

O CRQ, por sua vez, define que para responsabilidade técnica das indústrias de alimento (considera a água mineral como um alimento) o profissional adequado é o Engenheiro químico, o 
químico ou o técnico em química. Por esse motivo, durante as vistorias, impõe multas às empresas que não apresentarem à sede do Conselho um comunicado informando que há, pelo menos, um profissional da área de química apoiando o trabalho na indústria seja como contratado ou como consultor (CAETANO, 2005). Já o CREA, em obediência a lei que inclui a indústria de água mineral como atividade de extração mineral, exige que as empresas que envasam água mineral contratem um engenheiro de minas como responsável técnico. Mais uma vez instaura-se um conflito entre Entidades (Conselhos Profissionais) responsáveis pelas atribuições de profissionais de competências diferenciadas.

\section{CONCLUSÕES}

A partir da Constituição Federal de 1988, a visão de todo o conjunto, das diversas formas de aproveitamento de um mesmo recurso natural é levada em consideração, por meio da gestão integrada onde há a participação de todos os envolvidos (cidadãos, usuários, entidades e representantes dos poderes públicos municipal, estadual e federal). Os conflitos apontados neste trabalho decorrem, principalmente, da política centralizadora da legislação mineral de 1967, do anacronismo técnico-científico do Código das Águas Minerais de 1945, e da falta de adequação desta à Constituição Federal de 1988. Ainda, face às novas demandas decorrentes da evolução de outras políticas, como da saúde e ambiental, essa legislação sofreu acréscimo de normas e portarias, que permitiram ao setor competências específicas, que conflitam com a de outras instituições (federais a municipais).

Em relação ao profissional mais capacitado para se responsabilizar pela indústria de água mineral, na regulamentação da atividade profissional estabelecida pelo CREA, há base legal para que tantos geólogos quanto engenheiro de minas possam executar atividades de construção e de manutenção de poços. E, segundo os próprios órgãos de Saúde do país, qualquer profissional com cursos de especialização poderiam se responsabilizar pelas atividades de uma indústria de água mineral. Mais uma vez, fica caracterizada a necessidade da modernização da atitude prática pública que ainda está sob a influência de dispositivos legais antiquados e desatualizados, e mantém critérios estabelecidos em 1934, 1937 e 1945 quando ainda nem havia a profissão de geólogo. Essa atitude contradiz com a própria prática do DNPM que fiscaliza, normalmente, as indústrias de águas minerais com seu corpo de químicos, técnicos em mineração e geólogos.

Para que haja uma significativa diminuição nos conflitos é necessária que seja realizada pelos diversos organismos administrativos do Estado, a parte de análise de todo o processo de instalação da indústria de água mineral, desde a captação até o produto final envasado. As Instituições Federais seriam os grandes gerenciadores do aproveitamento dos recursos naturais (entre eles, os bens minerais) no país, já as Instituições Estaduais e Municipais, seus executores. A relação interinstitucional e parcerias são hoje uma necessidade ímpar na gestão de qualquer recurso natural.

Assim, acredita-se que essa proposta diminua os conflitos instaurados neste setor e esteja de acordo com as legislações mais modernas e democráticas, adequadas ao momento político do país, e ainda, contribua para a perfeita atuação do novo marco regulatório do Código de Minas.

\section{REFERÊNCIAS}

AFFONSO, A.O.E; MONSORES, A.L.M. O conflito conceitual entre as águas subterrâneas e águas minerais ï uma contribuição jurídica e técnica para uma gestão integrada entre recursos hídricos e 
minerais. In: Anais... XIII Congresso Brasileiro de Águas Subterrâneas. ABAS. Fortaleza - CE, 2004. 8p.

BRASIL. Decreto-lei no 24.642, de 10 de julho de 1934. Código de Minas. Diário Oficial [da] República dos Estados Unidos do Brasil, Rio de Janeiro, DF, 20 jul. 1934.

BRASIL. Decreto-lei no 4.147, de 04 de março de 1942. Dispõe sobre a fiscalização do comércio de águas engarrafadas. Diário Oficial [da] República dos Estados Unidos do Brasil, Rio de Janeiro, DF, 04 mar 1942.

BRASIL. Decreto-lei no 7.841, de 8 de agosto de 1945. Código de Águas Minerais. Diário Oficial [da] República dos Estados Unidos do Brasil, Rio de Janeiro, DF. 20 ago. 1945.

BRASIL. Lei Federal no 4.771 de 15 de setembro de 1965. Institui o Novo Código Florestal. Diário Oficial [da] República Federativa do Brasil, Brasília, DF. 16 de set. 1965.

BRASIL. Decreto-lei no 227, de 28 de fevereiro de 1967. Código de Minas. Diário Oficial [da] República Federativa do Brasil, Brasília, DF, 28 de fev. de 1967.

BRASIL. Conselho Federal de Engenharia, Arquitetura e Agronomia (CONFEA). Resolução n 218, de 29 de junho de 1973. Discrimina atividades das diferentes modalidades profissionais da Engenharia, Arquitetura e Agronomia. Diário Oficial [da] República Federativa do Brasil, Brasília, DF, 31 jul. 1973.

BRASIL. Decreto-lei ${ }^{\circ}$ 78.171, de 02 de agosto de 1976. Dispõe sobre o controle e fiscalização sanitária das águas minerais destinadas ao consumo humano. Diário Oficial [da] República Federativa do Brasil, Brasília, DF, 3 ago. 1976.

BRASIL. Ministério da Saúde e de Minas e Energia. Portaria 1.003, de 13 de agosto de 1976. Diário Oficial [da] República Federativa do Brasil, Brasília, DF, Brasília, DF, 24 ago. 1976.

BRASIL. Conselho Federal de Engenharia, Arquitetura e Agronomia (CONFEA). Resolução n ${ }^{\circ}$ 336, de 27 de outubro de 1989. Dispõe sobre o registro de pessoas jurídicas nos Conselhos Regionais de Engenharia, Arquitetura e Agronomia. Diário Oficial [da] República Federativa do Brasil, Brasília, DF, 16 nov. 1989.

BRASIL. Lei Federal no 9.433 de 08 de janeiro de 1997. Institui a Política de Recursos Hídricos, cria o Sistema Nacional de Gerenciamento de Recursos Hídricos. Diário Oficial [da] República Federativa do Brasil, Brasília, DF, Brasília, DF, 8 de jan. 1997.

BRASIL. Secretaria de Vigilância Sanitária do Ministério da Saúde. Portaria SVS/ MS no 326, de 30 de julho de 1997. Diário Oficial [da] República Federativa Brasil, Brasília, DF, 01 de ago. 1997.

BRASIL. Agência Nacional de Vigilância Sanitária. Resolução RDC no 54, de 15 de julho de 2000. Dispõe sobre o Regulamento Técnico para fixação de identidade e qualidade de água mineral natural e água natural. Diário Oficial [da] República Federativa do Brasil, Brasília, DF, Brasília, DF, 19 jun. 2000. 
BRASIL. Lei Federal no 9.985 de 18 de julho de 2000. Regulamenta o artigo 225, incisos I, II, II e IV da Constituição Federal, institui o Sistema Nacional de Unidades de Conservação da Natureza e dá outras providências. Diário Oficial [da] República Federativa do Brasil, Brasília, DF, Brasília, DF, 18 de jul. 2000.

BRASIL. Agência Nacional de Vigilância Sanitária. Resolução RDC no 259, de 20 de setembro de 2002. Diário Oficial [da] República Federativa Brasil, Brasília, DF, 23 set. 2002.

BRASIL. Agência Nacional de Vigilância Sanitária. Resolução RDC no 175, de 08 de julho de 2003. Aprova o Regulamento Técnico de Avaliação de Matérias Macroscópicas e Microscópicas Prejudiciais à Saúde Humana em Alimentos Embalados. Diário Oficial [da] República Federativa Brasil, Brasília, DF, 09 jul. 2003.

BRASIL. Agência Nacional das Águas (ANA). Resolução ANA no 317, de 26 de agosto de 2003. Diário Oficial [da] República Federativa do Brasil, Brasília, DF, Brasília, DF, 26 ago. 2003.

BRASIL. Conselho Nacional de Recursos Hídricos. Resolução n⿳ 76. Estabelece as diretrizes gerais entre a gestão de recursos hídricos e a gestão de águas minerais, termais, gasosas, potáveis de mesa ou destinadas a fins balneários. Diário Oficial [da] República Federativa Brasil, Brasília, DF, 27 nov. 2007.

BRASIL. Ministério de Minas e Energia, Departamento Nacional de Produção Mineral. Portaria 387, de 19 de setembro de 2008. Disciplina o uso das embalagens de plástico-garrafão retornáveis destinadas ao envasamento e comercialização de água mineral e potável de mesa e dá outras providências. Diário Oficial [da] República Federativa Brasil, Brasília, DF, 23 set. 2008.

BRASIL. Ministério de Minas e Energia, Departamento Nacional de Produção Mineral. Portaria 358, de 08 de outubro de 2009. Altera a Portaria 387, de 19 de setembro de 2008. Diário Oficial [da] República Federativa Brasil, Brasília, DF, 22 set. 2009.

BRASIL. Ministério de Minas e Energia, Departamento Nacional de Produção Mineral. Portaria 374, de 08 de outubro de 2009. Aprova a Norma Técnica que dispõe sobre as Especificações Técnicas para o aproveitamento de água mineral, termal, gasosa, potável de mesa, destinada ao envase, ou como ingrediente para o preparo de bebidas em geral ou ainda destinado para fins balneários, em todo o território nacional. Diário Oficial [da] República Federativa Brasil, Brasília, DF, 07 out. 2009.

CAETANO, L.C. A política da água mineral: uma proposta de integração para o estado do Rio de Janeiro. 2005. 281f.Tese (Doutorado em Geociências) - Universidade Estadual de Campinas - UNICAMP. Campinas. 2005.

CUNHA, A.S. Todas as Constituições Brasileiras. Campinas. Bookseller, 2001, 579p.

DEPARTAMENTO NACIONAL DE PRODUÇÃO MINERAL (DNPM). SIGMINE - Sistema de Informações Geográficas da Mineração. Disponível em: http://sigmine.dnpm.gov.br/sirgas2000/ RJ.zip, acesso: 15/05/2012.

HAGER, F.P.E; D’ALMEIDA, M.L. Águas subterrâneas e o direito constitucional. In: Anais... XV Congresso Brasileiro de Águas Subterrâneas. ABAS. Natal Ï RN, 2008, p: 1 a 15. 
INSTITUTO BRASILEIRO DE GEOGRAFIA E ESTATÍSTICA, IBGE. Malha Municipal do Estado do Rio de Janeiro, Disponível em: ftp://geoftp.ibge.gov.br/malhas _digitais/ município_ 2007/escala_2500mil/proj_geografica_sirgas2000/uf/rj/33mu2500grs.zip, acesso: 15/05/2012

INSTITUTO ESTADUAL DO AMBIENTE DO ESTADO DO RIO DE JANEIRO (INEA-RJ). Limites das Unidades de conservação do Estado do Rio de Janeiro. Comunicação pessoal em 10/03/2011. 2011.

PINTO, U.R. Consolidação da Legislação Mineral e Ambiental. 11ª Edição. Brasília. 2008. $670 \mathrm{p}$.

RIO DE JANEIRO. Lei Estadual no 3.239, de 02 de agosto de 1999. Instituiu a Política Estadual de Recursos Hídricos. Diário Oficial [do] Estado do Rio de Janeiro, RJ, 02 ago. 1999.

SCALON, M.G.B. Águas minerais e recursos hídricos: uma perspectiva de gestão integrada. Revista de Direito, Estado e Recursos Naturais, v. 1, n. 1, p. 131-160. 2011.

SERRA, S. H. Águas Minerais do Brasil. Campinas: Millenium, 2008. 272p. 